\title{
Psychopathological Consequences Related to Problematic Instagram Use Among Adolescents: The Mediating Role of Body Image Dissatisfaction and Moderating Role of Gender
}

\author{
Cemil Yurdagül $^{1} \cdot$ Kagan Kircaburun $^{2} \cdot$ Emrah Emirtekin $^{3} \cdot$ Pengcheng Wang $^{4}$. \\ Mark D. Griffiths ${ }^{5}$ iD
}

Published online: 11 April 2019

C The Author(s) 2019, corrected publication November 2019

\begin{abstract}
In a minority of cases, problematic use of technology can negatively impact on adolescents and impair some aspects of their social, emotional, and psychological development. The purpose of the present study was to examine the direct and indirect effects of problematic Instagram use (PIU) on different psychopathological outcomes including loneliness, depression, anxiety, and social anxiety via body image dissatisfaction (BID). Additionally, moderating role of gender on the relationships among variables was investigated. A total of 491 adolescents $\left(M_{\text {age }}=\right.$ 15.92 years, $\mathrm{SD}_{\text {age }}=1.07$; range $=14$ to 19 years) were recruited for the study to complete a questionnaire that included the relevant assessment tools for the aforementioned variables. Mediation and moderation analyses showed that among male adolescents, PIU was directly associated with loneliness, depression, general anxiety, and social anxiety and BID partially mediated these associations. Among females, PIU was directly associated with depression and indirectly with general anxiety and social anxiety via BID. Gender significantly moderated the direct relationships of PIU with loneliness, general anxiety, and social anxiety. PIU was directly associated with loneliness, general anxiety, and social anxiety among males only, whereas among females, PIU was indirectly associated with general and social anxiety via BID but was not related to loneliness. Results of this study indicate that PIU has different negative psychological effects on male and female adolescents and that BID appears to be one explanatory factor for these impairments especially among females.
\end{abstract}

\footnotetext{
The original article has been corrected: The article "Psychopathological Consequences Related to Problematic Instagram Use Among Adolescents: The Mediating Role of Body Image Dissatisfaction and Moderating Role of Gender", written by Cemil Yurdagül, Kagan Kircaburun, Emrah Emirtekin, Pengcheng Wang, and Mark D.

Griffiths, was originally published electronically on the publisher's internet portal (currently SpringerLink) on 11 April 2019 with a copyright designation of "`C Springer Science+Business Media, LLC, part of Springer Nature 2019". However, the article is in fact published on an open access basis.
}

Mark D. Griffiths

mark.griffiths@ntu.ac.uk

Extended author information available on the last page of the article 
Keywords Loneliness · Depression · Anxiety · Social anxiety · Problematic Instagram use $\cdot$ Body image $\cdot$ Internet $\cdot$ Internet addiction

Instagram is the second most popularly used social media platform among adolescents aged 13 to 17 years (72\%) after YouTube (85\%) (Anderson and Jiang 2018). Instagram allows users to share, like, and comment on photos, videos, stories, and live streams. Although Instagram can provide different advantageous gratifications such as expressing oneself, passing time, and entertainment, various detrimental effects related to Instagram use have also been reported (Kircaburun et al. 2018a). For instance, a recent report by the UK Royal Society for Public Health indicated Instagram to be the worst social media platform for young people's mental health and wellbeing among five platforms including Youtube, Snapchat, Facebook, and Twitter (Macmillan 2017).

Empirical studies have shown that frequency of Instagram use is associated with different problems among males and females including negative mood, body dissatisfaction, depressive symptoms, negative social comparison, loneliness, general and physical appearance anxiety, and lower self-esteem (Brown and Tiggemann 2016; Lup et al. 2015; Sherlock and Wagstaff 2018; Yang 2016). These psychosocial indicators can impair adolescent wellbeing and social, emotional, and psychological development (Grant et al. 2003). However, negative outcomes of problematic Instagram use (PIU) on adolescent psychopathology are still unclear and less is known about the possible mediating role of body image dissatisfaction (BID) on this relationship. Given that PIU can affect people more negatively than normal Instagram use (Kuss and Griffiths 2011, 2017), these aforementioned psychological impairments among adolescents may be more severe. Therefore, it is important to explore the direct and indirect effects of PIU on psychopathological outcomes including depression, loneliness, general anxiety, and social anxiety, while examining the mediating role of BID and moderating role of gender on this relationship.

\section{Problematic Instagram Use and Psychopathological Outcomes}

A growing body of evidence suggest that there is a bidirectional relationship between problematic social media use and psychopathological variables ( $\mathrm{Li}$ et al. 2018). Individuals become problematic users in attempts to cope with their real-life troubles and/or escape from their reality (Kircaburun and Griffiths 2018). However, they become more depressed, anxious, and lonely with the adverse effects of such use in one's life, including impairments in an individual's real-life social relationships, health, sleep, and eating patterns, as well as negative impacts on their occupational and/or educational responsibilities (Spada 2014). According to coping style theory, maladaptive coping execarbates negative emotions and mitigates positive emotions and wellbeing (Lazarus and Folkman 1984; Folkman and Lazarus 1988).

Given that problematic use of social networking sites is a maladaptive coping strategy (Andreassen 2015), PIU could lead to adverse psychological consequences. Moreover, some individuals become problematic online users while trying to compensate for their real-life social problems (Kardefelt-Winther 2014), and those who cannot compensate their social needs using social media (e.g., higher feelings of social support and belongingness) feel more lonely and isolated (Kuss and Griffiths 2011). Therefore, it is reasonable that PIU can facilitate higher psychopathology (i.e., depression, loneliness, general anxiety, and social anxiety).

Furthermore, empirical evidence specific to Instagram use has shown that Instagram broadcasting has been associated with higher loneliness which may be explained by frequent Instagram 
broadcasters not receiving the social support from their followers they were hoping for and feeling more isolated and lonely (Yang 2016). Frequency of Instagram use has also been correlated with elevated levels of depression, low self-esteem, and general anxiety in which individuals' proneness to compare their self-image with the images and videos of others they see on Instagram was an explanatory factor for these relationships (Sherlock and Wagstaff 2018). Another study also confirmed the negative effects of Instagram use on individuals' psychological wellbeing via reporting that spending time looking at celebrity and peer images on Instagram led to increased negative mood via state appearance comparison (Brown and Tiggemann 2016). Given that PIU is associated with more severe psychological damage than normal Instagram use (Andreassen 2015), PIU is likely to be associated with increased depression, loneliness, general anxiety, and social anxiety.

\section{The Mediating Role of Body Image Dissatisfaction}

Body image dissatisfaction (BID) has been defined as "the discrepancy between identification of one's own figure (actual) and the figure one chose as the desirable self-image (ideal)" (Forrest and Stuhldreher 2007; p.18) and is highly prevalent among adolescents (Neumark-Sztainer et al. 2002). According to body dissatisfaction theory, BID is associated with higher negative affect (Stice and Shaw 2002), which is a general predictor of elevated psychopathological symptoms and psychiatric disorders (Cohen et al. 2017; Watson et al. 1988). In addition, BID is associated with elevated depression, general anxiety, loneliness, and social anxiety (Aderka et al. 2014; Liang et al. 2016; Sharpe et al. 2018; Sujoldžić and De Lucia 2007). It may be that higher BID is an important factor that decreases adolescent self-esteem (Kostanski and Gullone 1998; Sujoldžić and De Lucia 2007), in which adolescents with impaired self-esteem become vulnerable to experience psychopathological symptoms (McWhirter et al. 2002; Sowislo and Orth 2013).

Despite the lack of empirical evidence concerning the relationship between PIU and BID, the frequency of Instagram use has been reported to predict higher BID (Brown and Tiggemann 2016; Hendrickse et al. 2017). Moreover, a systematic review comprising 20 studies indicated that social networking site use had a maladaptive effect on body image and was explained as being due to higher appearance-based social comparison (Holland and Tiggemann 2016). According to social comparison theory, individuals tend to compare their opinions and abilities with others' opinions and abilities (Festinger 1954). Females exposed to thin ideal body images appear to automatically engage in social comparison and has been related to increased negative thought accessibility (Bocage-Barthélémy et al. 2018). This might be the underlying explanation for the positive relationship between Instagram use and BID. Therefore, it is reasonable to assume that BID might explain the relationship between PIU and psychopathological symptoms.

\section{The Moderating Role of Gender}

The present study also investigates the moderating effect of gender on the direct and indirect relationships between variables because males and females vary on their scores of aforementioned variables. For example, systematic reviews have demonstrated that females generally report higher depression, general anxiety, and social anxiety than males (Dyrbye et al. 2006; Hofmann et al. 2010). BID has been found to be more prevalent among female adolescents and being female has been positively associated with higher problematic use of social media among adolescent students (Kircaburun et al. 2018b; Kostanski and Gullone 1998). Furthermore, female adolescents appear to 
have more adverse psychological effects from their BID when compared to males (Gestsdottir et al. 2018). Therefore, it is important to examine the possible moderating role of gender on the aforementioned relationships. However, because of the lack of studies that have evidenced a moderating role of gender in the direct and indirect relationships between PIU and psychopathological outcomes via $\mathrm{BID}$, instead of forming a specific hypothesis, the present study simply sought an answer to the research question of whether gender could significantly moderate the aforementioned relationships.

Despite the extant literature, it has not been empirically shown how PIU affects adolescent psychopathological symptoms and less is known about the mediating role of BID and moderating role of gender on these effects. Therefore, the purpose of the present study was to simultaneously investigate the direct and indirect relationship of PIU with depression, loneliness, general anxiety, and social anxiety via BID among total sample, as well as males and females separately while adjusting for frequency of Instagram use and age. The following hypotheses (Hs) and research questions (RQs) were formulated:

H1: PIU will be positively associated with BID, depression, loneliness, general anxiety, and social anxiety.

H2: BID will be positively associated with depression, loneliness, general anxiety, and social anxiety.

RQ1: Does gender moderate the direct relationship of PIU with BID, depression, loneliness, general anxiety, and social anxiety?

RQ2: Does gender moderate the indirect relationship of PIU with depression, loneliness, general anxiety, and social anxiety via BID?

\section{Methods}

\section{Participants and Procedure}

A total of 203 male and 288 female participants $\left(M_{\text {age }}=15.92\right.$ years, $\mathrm{SD}_{\text {age }}=1.07$; range $=14$ to 19 years) were recruited from a Turkish public Anatolian high school for the study. The chosen school is in an urban area (as opposed to a rural area) in which the research team believed would increase the likelihood of recruiting students who were regular Instagram users, the focus of investigation in this particular study. The present study adopted a convenience sampling method in which available students who were Instagram users were recruited. The total number of students in the school was 637. A total of 491 students were able to participate in the study during data collection (response rate $=77 \%$ ). The research team collected the data by visiting each classroom, informing the students about the aims of the study, and handing out 'paper-and-pencil' questionnaires. All participants were told that participation in the study was voluntary and all data were confidential and anonymous. Ethical approval for the study was received from the provincial directorate of national education committee and complied with the Helsinki declaration.

\section{Measures}

Bergen Facebook Addiction Scale (BFAS) The unidimensional BFAS (Andreassen et al. 2012) was used in this study by replacing the word 'Facebook' with 'Instagram'. This scale comprises six items (e.g., "How often in the past year have you become restless or troubled if you have been 
prohibited from using Instagram?") on a 5-point Likert scale from "very rarely" to "very often" that assess six components of addiction (i.e., salience, conflict, withdrawal, mood modification, tolerance, and relapse) outlined in the biopsychosocial framework of addiction (Griffiths 2005). The BFAS has been widely used and adapted to assess problematic (i.e., addictive) use of different social media applications (e.g., Andreassen 2015; Andreassen et al. 2016; Bányai et al. 2017). Turkish adaptation was done via following standard back-to-back translation process (Beaton et al. 2000). The Turkish version had good structural validity in the present study $\left(\chi^{2} / d f=1.94\right.$, RMSEA $=.04$ [CI 90\% $(.00, .08)], \mathrm{SRMR}=.02, \mathrm{CFI}=.99, \mathrm{GFI}=.99)$. The internal consistency coefficient was also high in the present study (Cronbach's $\alpha=.83$ ). Instagram use was also assessed by asking participants to indicate their daily time spent on Instagram.

Body Image Dissatisfaction Scale (BIDS) The unidimensional BIDS (Harter 2012) comprises five items (e.g., "I am not pleased with my physical appearance") on a 4-point Likert scale from "absolutely disagree" to "very true" that assess the dissatisfaction levels of adolescents with their body image. The Turkish adaptation with the adolescent sample indicated good structural validity $\left(\chi^{2} / d f=2.47, \mathrm{RMSEA}=.06[\mathrm{CI} 90 \%(.00, .13)], \mathrm{SRMR}=.03, \mathrm{CFI}=.99\right.$, $\mathrm{GFI}=.99$ ) of the scale (Kircaburun et al. 2018c). The internal consistency was high in the present study $(\alpha=.85)$.

UCLA Loneliness Scale Short Form (ULS-4) The unidimensional ULS-4 (Russell et al. 1980) comprises four items (e.g., "I can find companionship when I want it") on a 4-point Likert scale from "never" to "always" that assess perceived feeling of loneliness. The Turkish form of the scale has good psychometric properties in previously exploratory and confirmatory factor analyses (Eskin 2001). The internal consistency was adequate in the present study $(\alpha=.72)$.

Short Depression-Happiness Scale (SDHS) The unidimensional SDHS (Joseph et al. 2004) comprises six items on a 4-point Likert scale from "never" to "often" that assess depression and happiness levels of the participants. The Turkish form of the scale comprises three items that assess depressive symptoms (e.g., "I felt that life was meaningless") and has good structural validity (Kircaburun et al. 2018b). The internal consistency was high in the present study $(\alpha=.85)$.

State-Trait Anxiety Inventory Short Form (STAI-6) The unidimensional STAI-6 (Marteau and Bekker 1992) comprises six items (e.g., "I am worried") on a 4-point Likert scale from "almost never" to "almost always" that assess trait anxiety levels of participants. The Turkish form of the scale has good structural validity (Le Compte and Oner 1976). The internal consistency was good in the present study $(\alpha=.76)$.

Social Anxiety Scale Short Form (SAS-A) The SAS-A (Nelemans et al. 2017) comprises 12 items on a 5-point Likert scale from "never" to "always", consisting of factors which are social avoidance and distress-general (e.g., "I'm afraid to invite others to do things with me because they might say no"), social avoidance and distress-new (e.g., "I get nervous when I meet new people"), and fear of negative evaluation (e.g., "I worry about what others think of me"). However, the scale can be used unidimensionally (Nelemans et al. 2017). The Turkish form of the scale has good structural validity (Aydın and Sütcü 2007). The internal consistency was very high in the present study $(\alpha=.90)$. 


\section{Statistical Analysis}

Descriptive statistics were used to calculate mean scores and standard deviations of the study variables. Next, Pearson's correlation test was used to determine correlation coefficients between variables. These analyses (i.e., descriptives, $t$-tests, and correlation tests) were run via using SPSS 23.0 software. Next, path analyses (i.e., mediation and moderation analyses) were carried out via using AMOS 23.0 software with 5000 bootstrapped samples and $95 \%$ bias-corrected confidence intervals. In order to calculate the significance levels of the indirect pathways, Gaskin's (2016) estimand, ABindirectEffects.AmosEstimandVB, was used. The present study tested a saturated mediation model in the path analysis and used confirmatory factor analysis to calculate the psychometric properties of the scales. According to $\mathrm{Hu}$ and Bentler (1999), in order to indicate good model fit, values of goodness of fit indices (GFI) and comparative fit indices (CFI) should be higher than .95. Moreover, root mean square residuals (RMSEA) and standardized root mean square residuals (SRMR) should be lower than .05. Next, a multi-group analysis was run to test the moderating effect of gender on the direct and indirect associations between study variables. In order to calculate the significance levels of the differences across gender, Gaskin (2016) estimands, MyGroupDifferences.AmosEstimandVB and MyModMed.AmosEstimandVB, were used.

\section{Results}

The BFAS was used to assess problematic Instagram use for the first time. Therefore, confirmatory factor analysis was used to determine structure validity of the scale. Analysis indicated a good fit for the scale $\left(\chi^{2} / d f=1.94\right.$, RMSEA $=.04$ [CI 90\% $(.00, .08)$ ], SRMR = $.02, \mathrm{CFI}=.99$, GFI $=.99$ ). Findings related to descriptive statistics and correlations are presented in Table 1. Participants' score differences according to their gender were examined via $t$ tests. Female adolescents had significantly higher scores on all study variables compared to males (not shown - these are available from the corresponding author on request). Next, in order to test the model, path analysis was utilized with total sample, males, and females separately (Fig. 1). Among total sample, problematic Instagram use (PIU) was directly and indirectly associated with depression, general anxiety, and social anxiety via body image dissatisfaction (BID), while BID fully mediated the relationship between PIU and loneliness. Among male adolescents, BID was a partial mediator between PIU and psychopathological outcomes including depression $(\beta=.05, p<.05 ; 95 \%$ CI $[.00, .12])$, social anxiety $(\beta=.03$, $p<.05 ; 95 \%$ CI $[.00, .10])$, general anxiety $(\beta=.06, p<.05 ; 95 \%$ CI $[.00, .14])$, and loneliness $(\beta=.07, p<.05 ; 95 \%$ CI $[.00, .16])$. PIU had moderate effects on males' general and social anxiety but affected loneliness and depression only weakly. Finally, the relationship of PIU with general anxiety $(\beta=.10, p<.01 ; 95 \%$ CI $[.00, .17])$ and social anxiety $(\beta=.10, p<.01$; $95 \%$ CI $[.00, .16])$ was fully explained by BID among females. PIU was directly associated with depression and indirectly via BID, but was not associated with loneliness (Table 2).

In addition to mediation analyses, multi-group moderation analysis was applied to test the significance of the direct and indirect relationship differences between males and females. There was a significant moderating effect of gender on the direct relationships between PIU and loneliness $(\beta=.14 ; p<.05 ; 95 \%$ CI $[.07, .20])$, PIU and general anxiety $(\beta=.21 ; p<.01$; $95 \% \mathrm{CI}[.13, .28])$, PIU and social anxiety $(\beta=.65 ; p<.001 ; 95 \% \mathrm{CI}[.46, .79])$, and BID and social anxiety $(\beta=-.63 ; p<.05 ; 95 \% \mathrm{CI}[.37, .85])$. PIU was significantly directly associated 
Table 1 Mean scores, standard deviations, and Pearson's correlations among total sample

$\begin{array}{lllllllll}1 & 2 & 3 & 4 & 5 & 6 & 7 & 8\end{array}$

1. Problematic Instagram use

2. Body image dissatisfaction

3. Loneliness

4. Depression

$.25 * * * \quad$

5. General anxiety

$.14 * * .37 * * * \quad-$

6. Social anxiety

$.25 * * *$

7. Age

8. Instagram use

M

$.22 * * *$

$28 * * * 2.43 * * *$

$\begin{array}{lll}-.10 * & .02 & 07\end{array}$

$.49 * * * \quad .13 * * \quad .03$

$\begin{array}{lll}11.11 & 11.50 \quad 7.97\end{array}$

5.08

3.58

2.68

$* p<.05, * * p<.01, * * * p<.001$

with loneliness, general anxiety, and social anxiety only among males. The direct effect of BID on social anxiety was significantly stronger among females compared with males. Consequently, gender did not moderate the relationships of PIU with BID and depression, or BID with depression, loneliness, and general anxiety.

\section{Discussion}

The aim of the present study was to test direct and indirect role of PIU on psychopathological symptoms of depression, loneliness, general anxiety, and social anxiety via BID among male

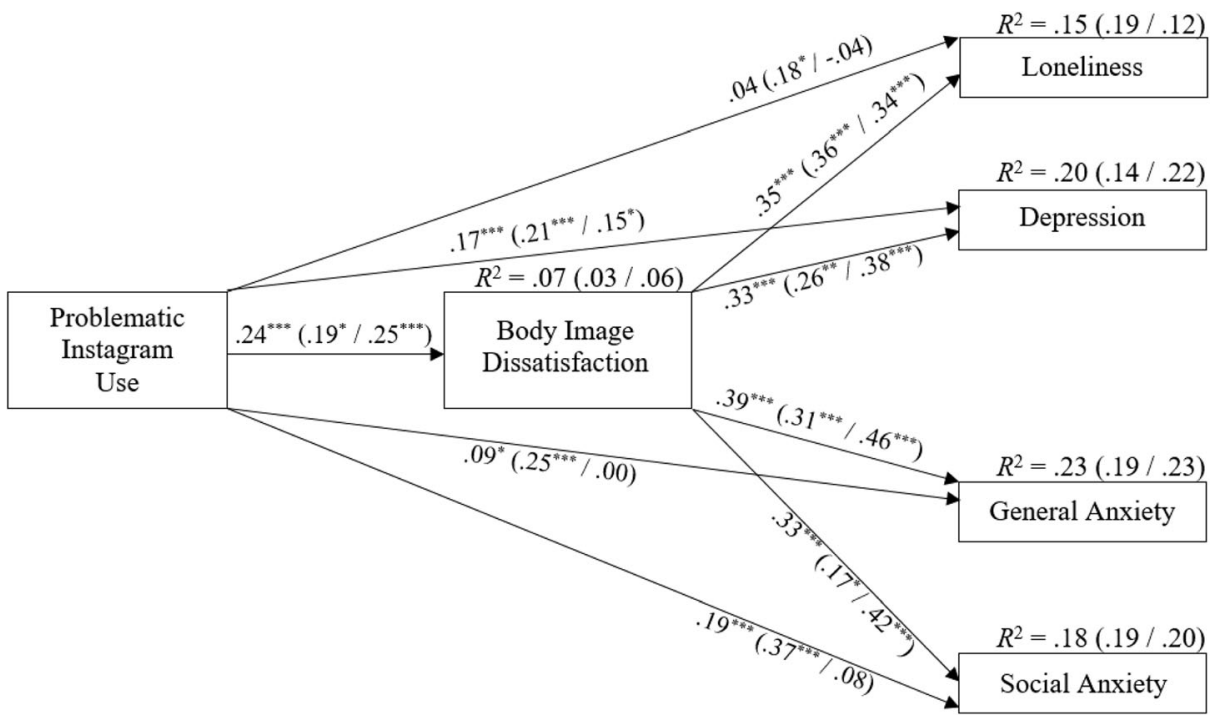

Fig. 1 Final model of the significant path coefficients. The values out of the brackets represent the standardized path coefficients among total sample. The first value (left) in brackets represents the standardized path coefficients among males, whereas values in the right side of the brackets describe path coefficients among females. Age and Instagram use are included into the model as control variables. However, they are not depicted in the figure for clarity. For clarity, covariances among outcome variables are also not depicted. ${ }^{*} p<.05$, ${ }^{* *} p<.01,{ }^{* * *} p<.001$ 
Table 2 Standardized estimates of total, direct, and indirect effects of problematic Instagram use

\begin{tabular}{|c|c|c|c|}
\hline & \multicolumn{3}{|l|}{ Effect (S.E.) } \\
\hline & Total sample & Males $(N=203)$ & Females $(N=288)$ \\
\hline PIU $\rightarrow$ loneliness (total effect) & $.12 *(.05)$ & $.25^{* *}(.09)$ & $.05(.06)$ \\
\hline PIU $\rightarrow$ loneliness (direct effect) & $.04(.05)$ & $.18 *(.07)$ & $-.04(.07)$ \\
\hline $\mathrm{PIU} \rightarrow \mathrm{BID} \rightarrow$ loneliness (indirect effect) & $.08 * * *(.02)$ & $.07 *(.04)$ & $.09 * * *(.03)$ \\
\hline PIU $\rightarrow$ depression (total effect) & $.25 * * *(.04)$ & $.25 * * *(.06)$ & $.25 * * *(.05)$ \\
\hline $\mathrm{PIU} \rightarrow$ depression (direct effect) & $.17 * * *(.05)$ & $.20 * * *(.06)$ & $.15^{* *}(.06)$ \\
\hline PIU $\rightarrow$ BID $\rightarrow$ depression (indirect effect) & $.08 * * *(.02)$ & $.05 *(.03)$ & $.10 * * *(.03)$ \\
\hline PIU $\rightarrow$ general anxiety (total effect) & $.18^{* *}(.05)$ & $.31 * * *(.08)$ & $.12 *(.06)$ \\
\hline PIU $\rightarrow$ general anxiety (direct effect) & $.09 *(.05)$ & $.25 * * *(.07)$ & $.00(.05)$ \\
\hline $\mathrm{PIU} \rightarrow \mathrm{BID} \rightarrow$ anxiety (indirect effect) & $.09 * * *(.02)$ & $.06 *(.03)$ & $.11 * * *(.03)$ \\
\hline PIU $\rightarrow$ social anxiety (total effect) & $.26 * * *(.05)$ & $.40 * * *(.08)$ & $.19 * *(.06)$ \\
\hline PIU $\rightarrow$ social anxiety (direct effect) & $.19 * * *(.05)$ & $.37 * * *(.08)$ & $.08(.06)$ \\
\hline PIU $\rightarrow$ BID $\rightarrow$ social anxiety (indirect effect) & $.08 * * *(.02)$ & $.03 *(.02)$ & $.11 * * *(.03)$ \\
\hline
\end{tabular}

$P I U$ problematic Instagram use, BID body image dissatisfaction

$* p<.05, * * p<.01, * * * p<.001$

and female adolescents. Female adolescents had significantly higher scores on all study variables compared to males which was in line with existing studies reporting that females generally report higher problematic social media use, body image dissatisfaction, depression, general anxiety, and social anxiety (Dyrbye et al. 2006; Hofmann et al. 2010; Kircaburun et al. 2018b; Kostanski and Gullone 1998). It may be that females (when compared with males) are more prone to engage in problematic use of online applications that facilitate social interaction and more vulnerable to have elevated psychopathological symptoms. It has also been reported that females (when compared to males) are more vulnerable to engaging in maladaptive daydreaming, have a higher desire for fame, and can become obsessed with celebrities (Zsila et al. 2018), in which all these problematic factors may lead to higher involvement in social media.

As expected, PIU was positively directly associated with psychopathological symptoms among the total sample and males. This finding is in line with the literature reporting that higher frequency of Instagram use and broadcasting are associated with higher negative mood, depressive symptoms, loneliness, general anxiety, and lower self-esteem (Brown and Tiggemann 2016; Lup et al. 2015; Sherlock and Wagstaff 2018; Yang 2016). Given that spending more than 2 hours a day on social media is more likely to result in higher psychological distress (Macmillan 2017), this direct effect is expected because one of the symptoms of PIU is total preoccupation with Instagram (Griffiths 2005). This is also in line with a previous study reporting a moderate direct relationship of Internet addiction with depression, anxiety, and stress among undergraduates (Akin and Iskender 2011). It may be that being excessively exposed to unrealistically superior body images and profiles of others on Instagram leads to adolescents feeling themselves as incompetent, and in turn, psychologically distressed. Partially contradicting expectations, PIU was only directly associated with depression among females and indirectly with general and social anxiety via BID, but nonsignificantly with loneliness. It may be that females' psychopathological symptoms of general and social anxiety are fully explained by their elevated BID, which may indicate that focusing on BID for preventing such adverse psychological problems is more important than focusing on their PIU. Furthermore, it appears females' problematic use of Instagram does not lead 
them to higher feelings of loneliness, implying that they might find higher social belongingness while interacting with others on Instagram.

As hypothesized, BID was a positive mediator between PIU and psychopathology. PIU was associated with elevated BID, and in turn, BID was related to increased psychopathological symptoms. This indirect relationship, which has been demonstrated for the first time in the present study, makes intuitive sense because Instagram can contribute to an unrealistic beauty standard for adolescents by influencing their perception of an ideal body image with all the effects and editing tools used on shared photos and videos (Maggi 2016). In turn, adolescents with impaired body image may suffer from elevated symptoms of psychopathology. Higher BID is associated with maladaptive body image coping strategies such as appearance-fixing behaviors and experiential avoidance due to unwillingness to experience negative appearance-related thoughts and emotions (Mancuso 2016). Given that when individuals engage in negative coping behaviors to deal with their problems, they might experience decreased wellbeing (Lazarus and Folkman 1984), adolescents with elevated BID may be more vulnerable to having increased psychopathological symptoms in an attempt to avoid the negative feelings associated with BID. This mediator role was different among males and females with BID being a stronger mediator between PIU and psychopathological outcomes among females. This may be that females tend to have more PIU and are affected from their Instagram use more adversely compared with males (Gestsdottir et al. 2018), explaining the stronger role of BID on the aforementioned impairments.

These differences among males and females were further examined. There was a significant gender moderation effect on these relationships. BID may explain why only a small proportion of the relationship between PIU and all psychopathological outcomes occured among males, while among females, BID fully mediated the associations of PIU with general and social anxiety, and partially with depression. In other words, female adolescents have significantly higher levels of BID than males and their perception of ideal thin body image is affected by their excessive exposure to attractive celebrity and peer images on Instagram (Brown and Tiggemann 2016), fully explaining their psychopathological consequences associated with PIU. However, there appears to be additional factors other than BID that explain the relationship of elevated PIU with psychopathological symptoms among males such as seeing others on Instagram who promote themselves as being extremely rich financially, very successful with the opposite sex, and successful in general (Macmillan 2017).

\section{Limitations and Conclusions}

There are several limitations to the present study that should be noted. First, the cross-sectional nature of the study prevents any causal conclusions on the results obtained. Future studies would need to use longitudinal design to test the model in the present study in order to establish causality between the variables examined. Second, the study group only comprised Turkish adolescent students which prevents generalization of the results to other age groups and other nationalities. Analysis with the proposed model in the present study should be replicated using participants from different age groups and cultures. Third, the data were all self-report and are therefore subject to well-known biases (such as memory recall and social desirability).

Despite its limitations, the present study is the first to empirically examine the adverse direct and indirect negative psychopathological consequences of PIU among adolescents via BID. Female adolescents had significantly higher scores on all study variables compared with males, and there was a significant mediating effect of BID and moderating effect of gender between 
PIU and adolescent psychopathology. PIU was directly and indirectly associated with depression, loneliness, social anxiety, and general anxiety via BID among males. However, females' PIU was indirectly associated with social and general anxiety via BID, and BID partially mediated the relationship between PIU and depression among females. BID was able to fully explain the relationship between PIU and female adolescents' social and general anxiety. The study provides empirical evidence that in order to prevent and/or reduce adolescent psychopathological symptoms, health professionals and clinicians should increase their focus on PIU and PIU-related BID, as well as take gender differences on these effects into account when treating such symptoms. More specifically, prevention and intervention strategies for female adolescents' PIU and psychopathology should give higher and more targeted focus on PIUrelated BID, whereas there appears to be other factors in addition to BID that may lead male adolescents to have elevated psychopathological symptoms that co-exist alongside their PIU.

Open Access This article is distributed under the terms of the Creative Commons Attribution 4.0 International License (http://creativecommons.org/licenses/by/4.0/), which permits unrestricted use, distribution, and reproduction in any medium, provided you give appropriate credit to the original author(s) and the source, provide a link to the Creative Commons license, and indicate if changes were made.

\section{Compliance with Ethical Standards}

Ethical approval for the study was received from the provincial directorate of national education committee and complied with the Helsinki declaration.

Conflict of Interest The authors declare that they do not have any interests that could constitute a real, potential or apparent conflict of interest with respect to their involvement in the publication. The authors also declare that they do not have any financial or other relations (e.g., directorship, consultancy, or speaker fee) with companies, trade associations, unions, or groups (including civic associations and public interest groups) that may gain or lose financially from the results or conclusions in the study. Sources of funding are acknowledged.

Ethical Approval All procedures performed in this study involving human participants were in accordance with the ethical standards of University's Research Ethics Board and with the 1975 Helsinki Declaration.

Informed Consent Informed consent was obtained from all participants.

Open Access This article is licensed under a Creative Commons Attribution 4.0 International License, which permits use, sharing, adaptation, distribution and reproduction in any medium or format, as long as you give appropriate credit to the original author(s) and the source, provide a link to the Creative Commons licence, and indicate if changes were made. The images or other third party material in this article are included in the article's Creative Commons licence, unless indicated otherwise in a credit line to the material. If material is not included in the article's Creative Commons licence and your intended use is not permitted by statutory regulation or exceeds the permitted use, you will need to obtain permission directly from the copyright holder. To view a copy of this licence, visit http://creativecommons.org/licenses/by/4.0/.

\section{References}

Aderka, I. M., Gutner, C. A., Lazarov, A., Hermesh, H., Hofmann, S. G., \& Marom, S. (2014). Body image in social anxiety disorder, obsessive-compulsive disorder, and panic disorder. Body Image, 11, 51-56.

Akin, A., \& Iskender, M. (2011). Internet addiction and depression, anxiety and stress. International Online Journal of Educational Sciences, 3, 138-148. 
Anderson, M., \& Jiang, J. (2018). Teens, social media \& technology 2018. Retrieved 09 October, 2018, from http://www.pewinternet.org/2018/05/31/teens-social-media-technology-2018/.

Andreassen, C. S. (2015). Online social network site addiction: A comprehensive review. Current Addiction Reports, 2, 175-184.

Andreassen, C. S., Torsheim, T., Brunborg, G. S., \& Pallesen, S. (2012). Development of a Facebook addiction scale. Psychological Reports, 110, 501-517.

Andreassen, C. S., Billieux, J., Griffiths, M. D., Kuss, D. J., Demetrovics, Z., Mazzoni, E., \& Pallesen, S. (2016). The relationship between addictive use of social media and video games and symptoms of psychiatric disorders: A large-scale cross-sectional study. Psychology of Addictive Behaviors, 30, 252-262.

Aydın, A., \& Sütcü, S. T. (2007). Validity and reliability of social anxiety scale for adolescents (SAS-A). Turkish Journal of Child and Adolescent Mental Health, 14, 79-89.

Bányai, F., Zsila, A., Király, O., Maraz, A., Elekes, Z., Griffiths, M. D., Andreassen, C. S., \& Demetrovics, Z. (2017). Problematic social media use: Results from a large-scale nationally representative adolescent sample. PLoS One, 12(1), e0169839.

Beaton, D. E., Bombardier, C., Guillemin, F., \& Ferraz, M. B. (2000). Guidelines for the process of cross-cultural adaptation of self-report measures. Spine, 25, 3186-3191.

Bocage-Barthélémy, Y., Chatard, A., Jaafari, N., Tello, N., Billieux, J., Daveau, E., \& Selimbegović, L. (2018). Automatic social comparison: Cognitive load facilitates an increase in negative thought accessibility after thin ideal exposure among women. PLoS One, 13, e0193200.

Brown, Z., \& Tiggemann, M. (2016). Attractive celebrity and peer images on Instagram: Effect on women's mood and body image. Body Image, 19, 37-43.

Cohen, J. N., Dryman, M. T., Morrison, A. S., Gilbert, K. E., Heimberg, R. G., \& Gruber, J. (2017). Positive and negative affect as links between social anxiety and depression: Predicting concurrent and prospective mood symptoms in unipolar and bipolar mood disorders. Behavior Therapy, 48, 820-833.

Dyrbye, L. N., Thomas, M. R., \& Shanafelt, T. D. (2006). Systematic review of depression, anxiety, and other indicators of psychological distress among US and Canadian medical students. Academic Medicine, 81, $354-373$.

Eskin, M. (2001). Adolescent loneliness, coping methods and the relationship of loneliness to suicidal behavior. Clinic Psychiatry, 4, 5-11.

Festinger, L. (1954). A theory of social comparison processes. Human Relations, 7, 117-140.

Folkman, S., \& Lazarus, R. S. (1988). Coping as a mediator of emotion. Journal of Personality and Social Psychology, 54, 466-475.

Forrest, K. Y., \& Stuhldreher, W. L. (2007). Patterns and correlates of body image dissatisfaction and distortion among college students. American Journal of Health Studies, 22, 18-25.

Gaskin, J., (2016). Plugins \& estimands. Gaskination's StatWiki. Retrieved 28 September, 2018, from http://statwiki.kolobkreations.com.

Gestsdottir, S., Svansdottir, E., Sigurðsson, H., Arnarsson, A., Ommundsen, Y., Arngrímsson, S. Á., et al. (2018). Different factors associate with body image in adolescence than in emerging adulthood: A gender comparison in a follow-up study. Health Psychology Report, 6, 81-93.

Grant, K. E., Compas, B. E., Stuhlmacher, A. F., Thurm, A. E., McMahon, S. D., \& Halpert, J. A. (2003). Stressors and child and adolescent psychopathology: Moving from markers to mechanisms of risk. Psychological Bulletin, 129, 447-466.

Griffiths, M. (2005). A 'components' model of addiction within a biopsychosocial framework. Journal of Substance Use, 10, 191-197.

Harter, S. (2012). Self-perception profile for adolescents: Manual and questionnaires. Denver: University of Denver.

Hendrickse, J., Arpan, L. M., Clayton, R. B., \& Ridgway, J. L. (2017). Instagram and college women's body image: Investigating the roles of appearance-related comparisons and intrasexual competition. Computers in Human Behavior, 74, 92-100.

Hofmann, S. G., Anu Asnaani, M. A., \& Hinton, D. E. (2010). Cultural aspects in social anxiety and social anxiety disorder. Depression and Anxiety, 27, 1117-1127.

Holland, G., \& Tiggemann, M. (2016). A systematic review of the impact of the use of social networking sites on body image and disordered eating outcomes. Body Image, 17, 100-110.

Hu, L. T., \& Bentler, P. M. (1999). Cutoff criteria for fit indexes in covariance structure analysis: Conventional criteria versus new alternatives. Structural Equation Modeling, 6, 1-55.

Joseph, S., Linley, P. A., Harwood, J., Lewis, C. A., \& McCollam, P. (2004). Rapid assessment of well-being: The short depression-happiness scale (SDHS). Psychology and Psychotherapy: Theory, Research and Practice, 77, 463-478.

Kardefelt-Winther, D. (2014). A conceptual and methodological critique of internet addiction research: Towards a model of compensatory internet use. Computers in Human Behavior, 31, 351-354. 
Kircaburun, K., \& Griffiths, M. D. (2018). Problematic Instagram use: The role of perceived feeling of presence and escapism. International Journal of Mental Health and Addiction. https://doi.org/10.1007/s11469-0189895-7.

Kircaburun, K., Alhabash, S., Tosuntaş, Ș. B., \& Griffiths, M. D. (2018a). Uses and gratifications of problematic social media use among university students: A simultaneous examination of the big five of personality traits, social media platforms, and social media use motives. International Journal of Mental Health and Addiction. https://doi.org/10.1007/s11469-018-9940-6.

Kircaburun, K., Kokkinos, C. M., Demetrovics, Z., Király, O., Griffiths, M. D., \& Çolak, T. S. (2018b). Problematic online behaviors among adolescents and emerging adults: Associations between cyberbullying perpetration, problematic social media use, and psychosocial factors. International Journal of Mental Health and Addiction. https://doi.org/10.1007/s11469-018-9894-8.

Kircaburun, K., Griffiths, M. D., \& Billieux, J. (2018c). Childhood emotional maltreatment and problematic social media use among adolescents: The mediating role of body image dissatisfaction. International Journal of Mental Health and Addiction. https://doi.org/10.1007/s11469-019-0054-6.

Kostanski, M., \& Gullone, E. (1998). Adolescent body image dissatisfaction: Relationships with self-esteem, anxiety, and depression controlling for body mass. The Journal of Child Psychology and Psychiatry and Allied Disciplines, 39, 255-262.

Kuss, D. J., \& Griffiths, M. D. (2011). Online social networking and addiction - A review of the psychological literature. International Journal of Environmental Research and Public Health, 8, 3528-3552.

Kuss, D. J., \& Griffiths, M. D. (2017). Social networking sites and addiction: Ten lessons learned. International Journal of Environmental Research and Public Health, 14, 311.

Lazarus, R. S., \& Folkman, S. (1984). Stress, appraisal, and coping. New York: Springer.

Le Compte, W. A., \& Oner, N. (1976). Development of the Turkish edition of the state-trait anxiety inventory. Cross-cultural Anxiety, 1, 51-67.

Li, J. B., Mo, P. K., Lau, J. T., Su, X. F., Zhang, X., Wu, A. M., et al. (2018). Online social networking addiction and depression: The results from a large-scale prospective cohort study in Chinese adolescents. Journal of Behavioral Addictions, 7, 686-696. https://doi.org/10.1556/2006.7.2018.69.

Liang, R., Ma, Z. L., \& Wang, K. (2016). Body image dissatisfaction in college students in mainland China: An exploratory study. International Journal of Psychology, 51, 138.

Lup, K., Trub, L., \& Rosenthal, L. (2015). Instagram\# instasad?: Exploring associations among instagram use, depressive symptoms, negative social comparison, and strangers followed. Cyberpsychology, Behavior and Social Networking, 18, 247-252.

Macmillan, A. (2017). Why Instagram is the worst social media for mental health. Retrieved 14 October, 2018, from http://time.com/4793331/instagram-social-media-mental-health/.

Maggi, A. (2016). How social media contributes to unrealistic beauty standards. Retrieved 14 October, 2018, from https://www.theodysseyonline.com/because-in-todays-social-media-frenzy-there-is-always-somethingto-edit.

Mancuso, S. G. (2016). Body image inflexibility mediates the relationship between body image evaluation and maladaptive body image coping strategies. Body Image, 16, 28-31.

Marteau, T. M., \& Bekker, H. (1992). The development of a six-item short-form of the state scale of the Spielberger state-trait anxiety inventory (STAI). British Journal of Clinical Psychology, 31, 301-306.

McWhirter, B. T., Besett-Alesch, T. M., Horibata, J., \& Gat, I. (2002). Loneliness in high risk adolescents: The role of coping, self-esteem, and empathy. Journal of Youth Studies, 5, 69-84.

Nelemans, S. A., Meeus, W. H., Branje, S. J., Van Leeuwen, K., Colpin, H., Verschueren, K., \& Goossens, L. (2017). Social anxiety scale for adolescents (SAS-A) short form: Longitudinal measurement invariance in two community samples of youth. Assessment. https://doi.org/10.1177/1073191116685808.

Neumark-Sztainer, D., Croll, J., Story, M., Hannan, P. J., French, S. A., \& Perry, C. (2002). Ethnic/racial differences in weight-related concerns and behaviors among adolescent girls and boys: Findings from project EAT. Journal of Psychosomatic Research, 53, 963-974.

Russell, D., Peplau, L. A., \& Cutrona, C. E. (1980). The revised UCLA loneliness scale: Concurrent and discriminant validity evidence. Journal of Personality and Social Psychology, 39, 472-480.

Sharpe, H., Patalay, P., Choo, T. H., Wall, M., Mason, S. M., Goldschmidt, A. B., \& Neumark-Sztainer, D. (2018). Bidirectional associations between body dissatisfaction and depressive symptoms from adolescence through early adulthood. Development and Psychopathology, 30, 1447-1458.

Sherlock, M., \& Wagstaff, D. L. (2018). Exploring the relationship between frequency of Instagram use, exposure to idealized images, and psychological well-being in women. Psychology of Popular Media Culture. https://doi.org/10.1037/ppm0000182.

Sowislo, J. F., \& Orth, U. (2013). Does low self-esteem predict depression and anxiety? A meta-analysis of longitudinal studies. Psychological Bulletin, 139, 213-240.

Spada, M. M. (2014). An overview of problematic internet use. Addictive Behaviors, 39, 3-6. 
Stice, E., \& Shaw, H. E. (2002). Role of body dissatisfaction in the onset and maintenance of eating pathology: A synthesis of research findings. Journal of Psychosomatic Research, 53, 985-993.

Sujoldžić, A., \& De Lucia, A. (2007). A cross-cultural study of adolescents - BMI, body image and psychological well-being. Collegium Antropologicum, 31, 123-130.

Watson, D., Clark, L. A., \& Carey, G. (1988). Positive and negative affectivity and their relation to anxiety and depressive disorders. Journal of Abnormal Psychology, 97, 346-353.

Yang, C. C. (2016). Instagram use, loneliness, and social comparison orientation: Interact and browse on social media, but don't compare. Cyberpsychology, Behavior and Social Networking, 19, 703-708.

Zsila, Á., McCutcheon, L. E., \& Demetrovics, Z. (2018). The association of celebrity worship with problematic internet use, maladaptive daydreaming, and desire for fame. Journal of Behavioral Addictions, 7, 654-664.

Publisher's Note Springer Nature remains neutral with regard to jurisdictional claims in published maps and institutional affiliations.

\section{Affiliations}

\section{Cemil Yurdagül $^{1} \cdot$ Kagan Kircaburun $^{2} \cdot$ Emrah Emirtekin $^{3} \cdot$ Pengcheng Wang $^{4} \cdot$ Mark D. $^{2}$ Griffiths $^{5}$}

Cemil Yurdagül

cemilyurdagul@gmail.com

Kagan Kircaburun

kircaburunkagan@gmail.com

Emrah Emirtekin

emrah.emirtekin@yasar.edu.tr

Pengcheng Wang

tianhai001@126.com

1 Faculty of Law, Ankara University, Ankara, Turkey

2 Educational Sciences Department, Duzce University, Duzce, Turkey

3 The Centre for Open and Distance Learning, Yaşar University, İzmir, Turkey

4 Department of Psychology, The Center of Internet + Social Psychology, Renmin University of China, Beijing, China

5 International Gaming Research Unit, Psychology Department, Nottingham Trent University, Nottingham, UK 